\title{
Smartwatch Detection of Undiagnosed Palpitations in a Juvenile
}

\author{
Keiko Toyohara ${ }^{1}$, Yoshimichi Kudo ${ }^{1}$, Daiji Takeuchi ${ }^{1}$ and Morio Shoda ${ }^{2}$
}

Key words: smartwatch, juvenile, palpitation, atrioventricular nodal reentrant tachycardia

(Intern Med Advance Publication)

(DOI: 10.2169/internalmedicine.8621-21)

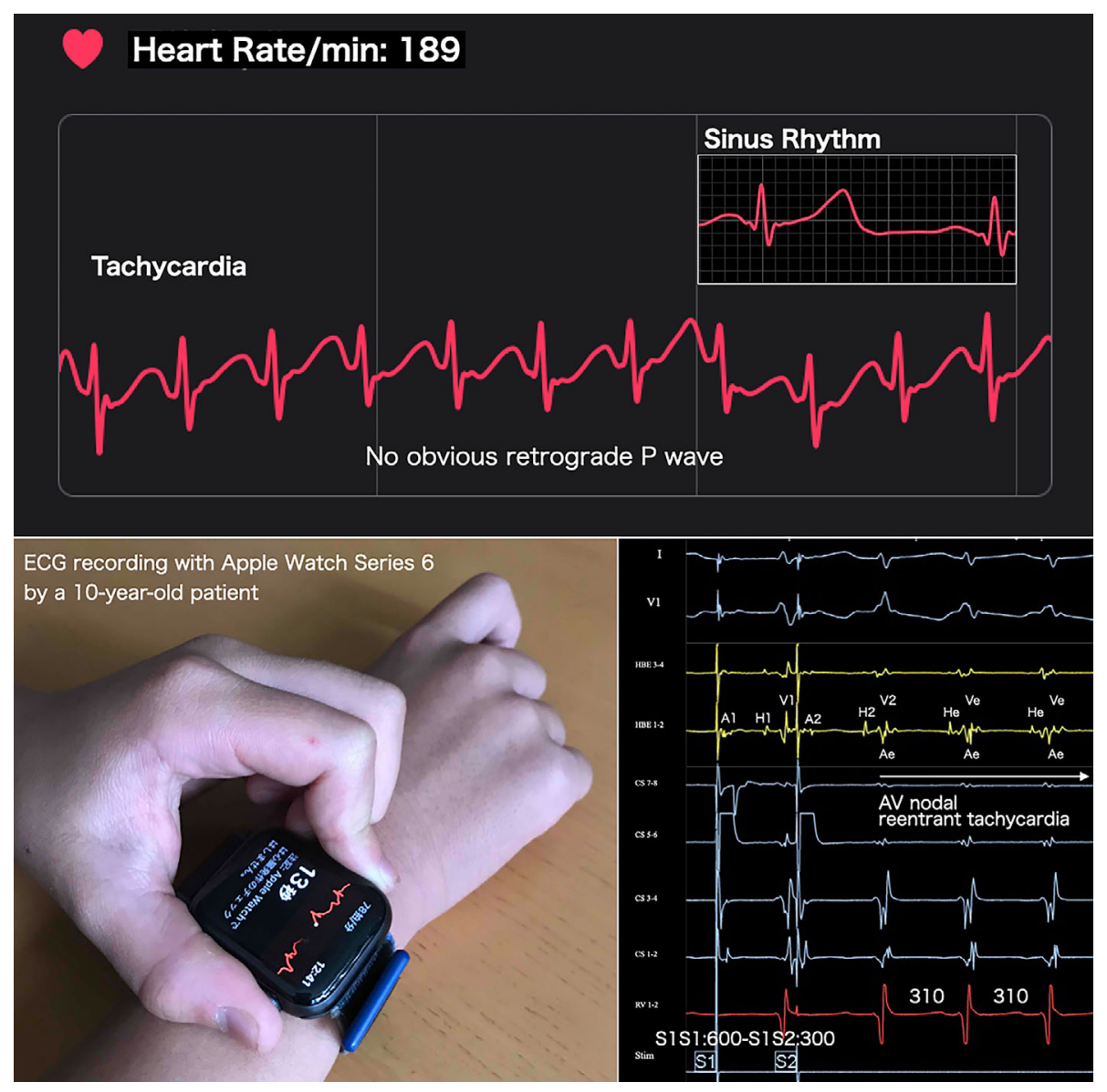

Picture.

A 10-year-old boy with a normal heart suffered from palpitations several times a week. Whenever he visited the hospital, the tachycardia disappeared and was not recorded by an electrocardiogram (ECG). We suggested his parents have him use an Apple Watch Series 6 despite being under the age limit (22 years old) for the ECG application. He experienced the same palpitations, which were recorded by his smartwatch. The ECG tracing presented a narrow QRS tachycardia with a heart rate of $189 \mathrm{bpm}$ and no obvious $\mathrm{P}$ waves (Picture), suggesting atrioventricular nodal reentrant

${ }^{1}$ Department of Pediatric Cardiology, Tokyo Women's Medical University, Japan and ${ }^{2}$ Clinical Research Division for Heart Rhythm Management, Department of Cardiology, Tokyo Women's Medical University, Japan

Received: September 8, 2021; Accepted: December 26, 2021; Advance Publication by J-STAGE: February 8, 2022

Correspondence to Dr. Morio Shoda, shoda.morio@twmu.ac.jp 
tachycardia. The patient subsequently underwent a catheter ablation procedure. The diagnosis was the same as that of the smartwatch, and the slow pathway was successfully eliminated by ablation. The Apple Watch Series 6 uses two electrodes (in the case and crown) to generate a single-lead ECG $(1,2)$ and is useful for monitoring symptoms caused by arrhythmias that are hard to detect by standard ECGs.

The authors state that they have no Conflict of Interest (COI).

\section{References}

1. Ahmed AS, Golden KM, Foreman JR, et al. Using a smartwatch to identify the morphology of atrial flutter. HeartRhythm Case Rep 6: 808-809, 2020.

2. Burke J, Haigney MCP, Borne R, et al. Smartwatch detection of ventricular tachycardia: Case series. HeartRhythm Case Rep 6: 800-804, 2020

The Internal Medicine is an Open Access journal distributed under the Creative Commons Attribution-NonCommercial-NoDerivatives 4.0 International License. To view the details of this license, please visit (https://creativecommons.org/licenses/ by-nc-nd/4.0/).

(C) The Japanese Society of Internal Medicine Intern Med Advance Publication 